\title{
Analyses of training needs to improve job performance using model Borich need assessment with theory of self-efficacy
}

\begin{abstract}
This purpose of the study is to identify the training needs of Iraqi agricultural extension workers in three (3) provinces. The study includes a conceptual framework, analytical framework, description of the study area, sources and procedures for data collection. The statistical tools used for analyzing the data collected are descriptive analysis, ANOVA one way, T-test and Chi-square, correlation analysis, Multiple Linear Regressions and also used model Borich needs assessment for measurement training needs. The objective of the study is to examine the relationship between the training needs of respondents in agricultural extension work and social demographic factors. This study revealed a significant relationship between training needs and provinces $(\mathrm{P}$-value $=0.029)$, marital status $(\mathrm{P}$-value $=0.007)$, number of training courses attended $(\mathrm{P}$-value $=0.149)$, location of work $(\mathrm{P}$-value $=0.007)$, training $(\mathrm{X} 2 \mathrm{P}$-value $=0.043$ ) and experience. Conversely, the relationship between training needs and specialization, age, gender, education level, origin, background of the family and experience in farming were found to be insignificant. T-test and Chi-Square statistical analyses were used to analyze the relationship between training needs and gender, experience in farming, family background, origin, and training courses attended. ANOVA analysis was used to analyze the relationship between training needs and provinces, specialization, work location and marital status. In addition, correlation analysis was also used to determine the relationship between training needs and age, experience in agricultural extension, education level and a number of training courses attended.
\end{abstract}

Keyword: Analyses; Training needs; Borich's need assessment model; Theory of selfefficacy 